DOI: $10.5216 /$ cab.v13i4.15354

\title{
EFEITOS DO EXTRATO DE PAREDE DE LEVEDURA EM DIETA SECA SOBRE A MICROBIOLOGIA, ÁCIDOS GRAXOS DE CADEIA CURTA E REDUÇÃO DO ODOR DAS FEZES DE GATOS ADULTOS
}

\author{
Adriana Augusto Aquino ${ }^{1}$, Mariana Pereira Alves $^{2}$, JoÃo Paulo Fernandes Santos $^{3}$, \\ MARCUS ANTÔNIO ROSSI FELICIANO ${ }^{4}$, ROBERTA HILSDORF PICCOLI ${ }^{5}$, FlÁVIA MARIA DE OLIVEIRA \\ BORGES SAAD 5 \\ ${ }^{1}$ Pós-Doutoranda da Faculdade de Medicina Veterinária e Zootecnia da USP, São Paulo, SP, Brasil. \\ ${ }^{2}$ Mestre pela Universidade Federal de Lavras, Lavras, MG, Brasil. \\ ${ }^{3}$ Pós-Graduando da Faculdade de Medicina Veterinária e Zootecnia da USP, São Paulo, SP, Brasil. \\ ${ }^{4}$ Pós-Doutorando da Faculdade de Ciências Agrárias e Veterinárias da UNESP, Jaboticabal, SP, Brasil - \\ marcusfeliciano@yahoo.com.br \\ ${ }^{5}$ Professores Doutores da Universidade Federal de Lavras, Lavras, MG, Brasil
}

\begin{abstract}
Objetivou-se avaliar os efeitos do extrato de parede de levedura (EPL) em dieta seca sobre a microbiota fecal, concentração de ácidos graxos de cadeia curta (AGCC) e redução do odor das fezes de gatos adultos. Foram utilizados 20 animais, dez de cada sexo, distribuídos ao acaso em quatro tratamentos e cinco repetições, totalizando 20 unidades experimentais: 1) dieta comercial seca (controle); 2) controle $+0,2 \% ; 3$ ) controle $+0,4 \%$; e 4) controle $+0,6 \%$ de EPL na matéria seca da dieta. Foram realizados contagem de enterobactérias, E.coli e bactérias láticas, concentração fecal dos ácidos acético, propiônico, butírico e nitrogênio amoniacal, além de
\end{abstract}

painel sensorial. Não foram observadas diferenças significativas $(p>0,05)$ para as contagens bacterianas e a concentração de AGCC e nitrogênio amoniacal; no entanto, por meio do painel sensorial pôde ser notada redução no odor das fezes com o uso de $0,2 \%$ de EPL na dieta. Concluiu-se que a adição de até $0,6 \%$ de EPL não teve efeito sobre a microbiologia e a concentração de ácidos graxos, mas há potencial uso como aditivo devido à melhora no odor das fezes. Outros estudos são necessários para compreender os mecanismos de ação, efeitos e níveis de inclusão desse prebiótico para gatos domésticos.

PALAVRAS-CHAVE: ácido butírico; bactérias láticas; felinos; mananoligossacarídeo; nitrogênio amoniacal.

\begin{abstract}
EFFECTS OF YEAST CELL WALL EXTRACT IN DRY DIET ON MICROBIOLOGY, SHORT-CHAIN FATTY ACIDS AND FECAL ODOR REDUCTION OF ADULT CATS
\end{abstract}

\section{ABSTRACT}

The aim of this study was to evaluate the effects of yeast cell wall extract (YCW) in dry diet on the fecal microbiota, concentration of short-chain fatty acids (SCFA) and on the odor reduction of cats feces. We used 20 animals of both sexes, randomly assigned to four treatments and five repetitions totaling 20 experimental units: 1) dry commercial diet (control); 2) control $+0.2 \%$, 3 ) control $+0.4 \%$, and 4 ) control $+0.6 \%$ of YCW in dry Ci. Anim. Bras., Goiânia, v.13, n.4, p. 479-486, out./dez. 2012 matter. Enterobacteriaceae and lactic acid bacteria, fecal concentration of acetic, propionic and butyric acids, ammonia nitrogen and sensory panel were performed. There were no significant differences $(p>0.05)$ for bacterial counts and the concentration of SCFA and ammonia, but in sensory panel a reduction in the odor of feces could be noted with the use of $0.2 \%$ of YCW. We concluded that the addition of up to $0.6 \% \mathrm{YCW}$ had no 
effect on the microbiology and the concentration of fatty acids, but there is potential for its use as an additive because of the improvement in the odor of feces.
However, further studies are needed to understand the mechanisms of action and the effects of prebiotics for domestic cats.

KEYWORDS: ammoniacal nitrogen; butyric acid; feline; lactic bacteria; mannanoligosacharide.

\section{INTRODUÇÃO}

Os prebióticos são ingredientes nutricionais não digeríveis que estimulam seletivamente o crescimento e a atividade de uma ou mais bactérias intestinais benéficas (GIBSON et al., 2004), destacando-se dentre as opções possíveis para melhorar a saúde animal e com potencial uso no tratamento de algumas afecções intestinais.

A parede celular da levedura Saccharomyces cerevisiae é constituída por $35-40 \%$ de mananoproteínas, $5-10 \%$ de 1,6 beta-glucano, 50$55 \%$ de 1,3 beta-glucano e $1-2 \%$ de quitina (KLIS et al., 2002). O mananoligossacarídeo (MOS) corresponde a quase $50 \%$ da fração carboidrato da parede e tem demonstrado capacidade de modular a microbiota intestinal gerando benefícios decorrentes da seleção bacteriana, tais como produção de ácidos graxos de cadeia curta e redução de odor de fezes. Isso é importante porque os ácidos graxos, além da nutrição das células intestinais, causam alterações do fluxo sanguíneo e da atividade muscular no cólon, proliferação de enterócitos e estimulação da produção de mucina, o que melhora a saúde intestinal (TELLEZ et al., 2006). Cabe comentar que são escassos os estudos sobre os efeitos desses elementos em felinos.

A seleção de bactérias benéficas promovida pela utilização do MOS, em detrimento de populações como clostridios e enterobactérias, pode alterar a utilização de nutrientes pelos microorganismos no intestino grosso e, assim, diminuir a produção de compostos oriundos do metabolismo da proteína, o que pode reduzir o mau odor das fezes (TORTORA et al., 2002). Espécies proteolíticas produzem compostos tóxicos ao passo que os ácidos graxos de cadeia curta, oriundos do metabolismo de outras espécies são interessantes por aumentar a produção de energia para o intestino (WALKER \& DUFFY, 1998).

O principal mecanismo por meio do qual o mananoligossacarídeo modula a microbiota é tornando-se sítio de ligação para determinadas bactérias gram-negativas, o que impede o acoplamento destas à superfície das células intestinais. Isso acontece devido à constituição particular desse grupo de bactérias que apresentam resíduos de $D$-manose em suas fímbrias. Patógenos com fímbria tipo 1 manose-específica adsorvem o
MOS prontamente e deixam o intestino sem possibilidade de colonizá-lo (BASSAN et al., 2008). Dessa forma, objetivou-se, por meio deste trabalho, avaliar o efeito de diferentes níveis de extrato de parede de levedura (EPL) $(0 ; 0,2 ; 0,4$ e $0,6 \%)$ em dieta seca sobre a contagem de bactérias láticas, enterobactérias e Escherichia coli, e concentração de ácidos graxos de cadeia curta.

\section{MATERIAL E MÉTODOS}

Foram utilizados 20 gatos adultos, sem raça definida, dez machos e dez fêmeas, com peso médio de $3,56 \mathrm{~kg} \pm 0,78 \mathrm{~kg}$, com escore corporal 5 (na escala de 1 a 9 segundo LAFLAMME, 1997), alojados em gaiolas metabólicas durante todo o período experimental. Todo o procedimento experimental foi aprovado pela Comissão de Ética na Pesquisa e Utilização Animal da Universidade Federal de Lavras, processo ${ }^{\circ}$ 003/2007.

$\mathrm{O}$ delineamento experimental foi inteiramente casualizado, com quatro tratamentos e cinco repetições, totalizando 20 unidades experimentais. Foram destinados 21 dias de adaptação seguidos por quatro de coleta de fezes frescas para análises de microbiologia (contagem total de enterobactérias, Escherichia coli e bactérias láticas), ácidos graxos de cadeia curta, nitrogênio amoniacal e teste sensorial para avaliação do potencial de redução do odor das fezes.

Os tratamentos fornecidos a cada um dos grupos foram: (1) controle, dieta comercial seca padrão; (2) dieta comercial seca + inclusão de $0,2 \%$ EPL; (3) dieta comercial seca padrão + 0,4\% EPL; e (4) $0,6 \%$ de EPL na matéria seca da dieta.

As quantidades de alimento oferecidas foram baseadas nas necessidades energéticas estimadas pela equação $100 \times \mathrm{PC}^{0,67}$ (NATIONAL RESEARCH COUNCIL, 2006). Para mistura da EPL, o escore corporal foi determinado no início e ao final do período experimental e todos os animais apresentaram-se entre o escore 3, considerado ideal para gatos, segundo a escala de 1 a 5 . Quantidade padronizada de água (1,92 vezes o peso da ração) foi acrescida e o alimento foi processado em liquidificador. Posteriormente, a quantidade para cada animal foi individualmente pesada e o EPL misturado. A composição química e básica analisada da dieta seca foi de: 1) para matéria natural seca, 
obteve-se $7,17 \%$ de umidade, $32.34 \%$ de proteína e $6,62 \%$ de matéria mineral; 2) para matéria seca, verificou-se $34,83 \%$ proteína e $7,13 \%$ de matéria mineral.

Foi utilizada uma dieta comercial padrão para felinos adultos com a seguinte composição: arroz quebrado, farinha de vísceras, farelo de glúten de milho 60, milho integral moído, farelo de soja, farinha de peixe, gordura de frango, carne de ovelha em pó, semente de linhaça, hidrolisado de frango ou subprodutos, fosfato bicálcico, cloreto de sódio, cloreto de potássio, colina e premix vitamínico mineral. As análises bromatológicas foram realizadas no laboratório de pesquisa animal da Universidade Federal de Lavras.

Foi determinada também a energia digestível para cada um dos tratamentos $(3769,61 ; 3623,29$; 3825,18 e $3832,11 \mathrm{kcal} / \mathrm{kg}$ para controle e inclusão de 0,$2 ; 0,4$ ou $0,6 \%$ de EPL, respectivamente) e, por meio das equações propostas pelo NRC (2006), foi determinada a energia metabolizável corrigida $(3577,01 ; 3434,89 ; 3624,70$ e $3624,19 \mathrm{kcal} / \mathrm{kg}$ para controle e inclusão de 0,$2 ; 0,4$ ou $0,6 \%$ de EPL, respectivamente).

A água oferecida aos animais foi avaliada quanto a sua potabilidade, segundo a resolução número 518 de 2004 (BRASIL, 2004). Tanto para água como para o alimento foram coletadas amostras para análises de coliformes totais e termotolerantes.

Para a análise das fezes, realizou-se a contagem total de bactérias do ácido lático e enterobactérias, usando-se ágar Man, Rogosa e Sharpe (MRS)/técnica de profundidade e ágar eosina azul de metileno (EMB)/técnica de superfície, respectivamente. Todas as análises microbiológicas seguiram metodologia descrita por SILVA et al. (2001).

Foram contadas as colônias maiores que $1 \mathrm{~mm}$, sendo os resultados expressos em log de $\mathrm{UFC} / \mathrm{g}$ de fezes. Em seguida, as colônias que cresceram nas placas de ágar eosina azul de metileno (EMB) foram isoladas e plaqueadas para testes confirmativos para E. coli. A partir de culturas de colônias isoladas em PCA, fez-se a coloração de Gram e inoculou-se nos meios teste para a realização das provas bioquímicas de indol, VM (vermelho de metila), VP (Voges Proskauer) e citrato, na série denominada IMViC. Foram consideradas positivas para E. coli as colônias que se apresentaram como bastonetes gram negativos, indol positivo ou negativo, VM positivo, VP negativo e citrato negativo.

As amostras de fezes coletadas até 15 minutos após a defecação foram conservadas em ácido clorídrico $2 \mathrm{~N}$ e congeladas até o momento das análises que seguiu a metodologia da AOAC (1995). Após serem descongeladas, uma alíquota de $50 \mathrm{~mL}$ de cada uma das amostras foi transferida para o tubo de digestão onde realizou-se a destilação após a adição de $2 \mathrm{~mL}$ de água destilada, $5 \mathrm{~mL}$ de solução de cloreto de cálcio $5 \%$ e de algumas gotas de antiespumante. Recolheram-se cerca de $150 \mathrm{~mL}$ do destilado em erlenmeyer contendo $10 \mathrm{~mL}$ de solução de ácido bórico $4 \%$ e cerca de 3 gotas da solução indicadora vermelho de metila e verde de bromocresol 2:1. A titulação foi realizada com ácido clorídrico $0,05 \mathrm{~N}$ e o teor de $\mathrm{N}$-amoniacal calculado pela fórmula abaixo:

$$
\mathrm{N}-\mathrm{NH}_{3}(\mathrm{mg} \%)=\frac{(\text { vol. HCL } \times \text { normal. HCL } \times 0,014 \times 100}{\mathrm{mL} \text { de amostra }} \times 1000
$$

Cerca de $25 \mathrm{~g}$ de fezes correspondentes a cada um dos quatro tratamentos foram coletadas logo após a defecação para composição das amostras. $\mathrm{O}$ tratamento controle recebeu a designação de padrão $(\mathrm{P})$ e cada uma das outras amostras (1, 2 e 3 ) foram comparadas em relação ao controle no que diz respeito ao odor: se melhor, igual ou pior de acordo com um sistema de escore que variou de zero a quatro onde: 0) amostra com odor extremamente pior que o do padrão; 1) pior que o padrão; 2) igual ao padrão; 3 ) melhor que o padrão; e 4) muito melhor que o padrão.

Um total de 51 pessoas participou individualmente do teste e, entre as amostras, recebiam um copo de pó de café, com o objetivo de eliminar os resíduos de odor referentes ao da amostra anterior, que poderiam comprometer a avaliação sensorial. O teste foi realizado no período da manhã (das 8 às 11) e teve duração de três horas. A metodologia aplicada nesse teste sensorial foi adaptada do proposto por MAIA (2010).

Para as análises de AGCC, segundo metodologia adaptada de ERWIN et al. (1961), as fezes foram coletadas até 15 minutos após a defecação, acidificadas com $10 \mathrm{~mL}$ de ácido clorídrico a $2 \mathrm{~N}$ e congeladas até o momento das análises. As mensurações dos ácidos acético, propiônico e butírico foram feitas a partir do sobrenadante das alíquotas de fezes centrifugadas com ácido metafosfórico $25 \%$, em cromatógrafo de 
gás Shimadzu modelo 17A, equipado com coluna nukol $(30 \mathrm{~cm} \times 0,53 \mathrm{~mm})$. O nitrogênio foi o gás carreador, sendo a temperatura inicial de $50^{\circ} \mathrm{C}$ e a final de $180^{\circ} \mathrm{C}$ e o fluxo e pressão de acordo com o file específico. $\mathrm{O}$ aparelho foi calibrado com padrões dos ácidos acético, propiônico e butírico a uma concentração de $0,5 \%$.

O cálculo para a concentração de cada um dos ácidos presentes na amostra está demonstrado abaixo:

$$
\% \text { AGCC na MS fezes }=\left(\frac{(\text { dens. } \times \text { conc }) \times(\text { pur. } \times \text { vol. padrão inj. })}{100}\right) \times\left(\frac{\text { área amostra }}{\text { área padrão }}\right) \times\left(\frac{\text { umidade }}{\text { vol. amostra inj. }}\right) \times\left(\frac{100}{\text { MSD }}\right)
$$

Em que: conc. $=$ concentração do padrão injetado; dens. $=$ densidade do ácido; MS fezes= matéria seca das fezes; $\mathrm{MSD}=$ matéria seca definitiva

AGCC total $=$ conc de acético + conc. de propiônico + conc. de butírico

Em que: conc. $=$ concentração do respectivo ácido em \% na matéria seca das fezes

Os resultados foram analisados por meio do programa computacional Statistical Analysis System (SAS Institute Inc., 2004), sendo previamente verificada a normalidade dos resíduos pelo teste de SHAPIRO-WILK (PROC UNIVARIATE) e as variâncias comparadas pelo teste de HARTLEY. Para dados não paramétricos utilizou-se teste de Kruskal Wallis, pelo PROC NPAR1WAY do SAS. Em todas as análises, considerou-se um nível de significância de $5 \%$.

\section{RESULTADOS E DISCUSSÃO}

A ingestão de matéria seca foi de 52,05; 53,$86 ; 54,33$ e 42,18 gramas para os tratamentos controle, 0,$2 ; 0,4$ e $0,6 \%$, respectivamente, o que correspondeu a $80 \%$ da quantidade fornecida e calculada segundo a equação do NRC (2006). O peso dos animais foi mantido do início ao final do experimento e o consumo de proteína e lipídeos atendeu às recomendações preconizadas pela Association of American Feed Control Officials (mínimo de 15,50 g de proteína e de $3 \mathrm{~g}$ de lipídeos).

$\mathrm{O}$ cultivo laboratorial das amostras de fezes dos felinos em meio EMB possibilitou a observação de 11 colônias com características fenotípicas distintas, conforme descrito: 1- centro enegrecido e halo verde metálico; 2- roxas com centro enegrecido e a presença de halo róseo escuro; 3- roxas com centro enegrecido sem a presença de halo; 4- róseas escuras; 5- arroxeadas com a presença de halo róseo; 6- róseas apresentando halos esbranquiçados; 7- róseas de tonalidade clara, sem halo; 8- roxas com halo lilás; 9- róseas com halo rosa de tonalidade clara; 10- centro róseo/arroxeado e apresentando halo arroxeado/esverdeado; 11 - vinho.

Notou-se maior concentração das colônias 2 , 3 e 4 em todos os animais estudados. As demais não se apresentaram em proporções consideráveis ou estiveram relegadas a um único tratamento, com exceção da colônia número 5 que esteve distribuída nos três primeiros, mas ausente no tratamento de $0,6 \%$. O baixo percentual de algumas das colônias descritas nesse experimento pode ser devido à contaminação ambiental ou mesmo expressão fenotípica diferenciada.

Sabe-se que, embora as colônias bacterianas apresentem características específicas em um determinado meio de cultura, condições de crescimento (como o tempo de desenvolvimento da colônia, a interação/competição com outras bactérias, entre outros) podem interferir decisivamente sobre a expressão destas (HOLT, 1997).

Das onze colônias encontradas, três (as de número 1,2 e 3 ) foram confirmadas como E. coli pelo teste de IMViC, associado à coloração de Gram. Essas se apresentaram como bastonetes gramnegativos e responderam negativamente ao citrato e ao Voges-Proskauer, mas positivamente ao indol e o vermelho de metila.

A E. coli representou $72,30 \%$ de todas as enterobactérias isoladas neste experimento, correspondendo a $65,71 \%, 56,21 \%, 73,38 \%$ e $93,91 \%$ do total nos tratamentos 1 a 4, respectivamente. Em meio MRS, as colônias eram pequenas, em formato puntiforme ou arredondado, brancas e sem presença de halos.

Não houve diferença significativa $(p>0,05)$ para as contagens de Enterobacteriaceae, E. coli ou bactérias láticas, bem como para a relação entre bactérias láticas e E.coli, conforme demonstrado na Tabela 1. 
Tabela 1: Contagem microbiológica total fecal de gatos em função dos níveis de inclusão de extrato de parede de levedura (EPL) na dieta seca empregada no estudo

\begin{tabular}{lcccccccc}
\hline & \multicolumn{3}{c}{ Tratamentos (\% EPL) } \\
\hline Variável & 0 & 0,2 & 0,4 & 0,6 & CV & L & Q & D \\
\hline BAL $(\log / g)$ & 8,33 & 7,93 & 8,76 & 7,85 & 15,07 & 0,81 & 0,66 & 0,27 \\
EBT $(\log / g)$ & 6,47 & 5,74 & 6,31 & 5,80 & 14,56 & 0,44 & 0,78 & 0,2 \\
E.coli $(\log / g)$ & 5,94 & 5,41 & 6,05 & 5,34 & 14,29 & 0,52 & 0,82 & 0,17 \\
REL & 1,46 & 1,46 & 1,48 & 1,46 & 17,71 & 0,99 & 0,96 & 0,92 \\
\hline
\end{tabular}

p*: significância p< 0,05; \% EPL: porcentagem de extrato de parede de levedura; CV: coeficiente de variação; L:efeito linear; Q: efeito quadrático; D: efeito desvio. BAL: Bactérias ácido-láticas; EBT: Enterobacteriaceae; REL: Relação bactéria lática/E.coli.

O número de bactérias láticas em $\log / \mathrm{g}$ de influenciado diretamente o estabelecimento das fezes neste experimento esteve acima das bactérias láticas, devido à competição pela adesão. A concentrações citadas por LEE et al. (2000), que aderência eficiente das bactérias probióticas é indicam um número maior que $10^{6}$ para atividade dependente de uma relação mais alta entre estas e probiótica. E.coli (LEE et al., 2002) e, no presente estudo, a

Níveis de EPL semelhantes aos utilizados relação manteve-se constante independentemente dos tem sido efetivos em outras espécies de animais tratamentos.

monogástricos, inclusive cães (MIDDELBOS et al., Efeitos das concentrações de EPL sobre a 2007), para modular a microbiota intestinal a partir da contagem total de enterobactérias também não foram ação sobre a E. coli. No entanto, o mecanismo de encontradas (p>0,05), pois grande parte das bactérias atuação do mananoligossacarídeo da parede da que crescem em meio EMB parecem não expressar as levedura é restrito às bactérias fímbria tipo 1 e ainda fímbrias tipo 1 . A redução seria esperada caso a não há relatos ou estudos que comprovem a interação do mananoligossacarídeo com a E.coli porcentagem dessas no intestino de felinos. Em tivesse ocorrido.

frangos elas chegam a $68 \%$ do total de bactérias As médias para o escore de percepção de intestinais da espécie (FINUCANE, 1999). odor (teste sensorial) das fezes e de nitrogênio

A ausência de efeito sobre a E.coli pode ter amoniacal estão demonstradas na Tabela 2.

Tabela 2: Concentração de nitrogênio amoniacal ( $\mathrm{mg} \%)$ e escore para odor de fezes de gatos alimentados com dieta seca acrescida de extrato de parede de levedura (EPL)

\begin{tabular}{lccccc}
\hline & \multicolumn{5}{c}{ Tratamentos $(\%$ EPL) } \\
\hline Variável & 0 & 0,2 & 0,4 & 0,6 & $\mathrm{p}^{*}$ \\
\hline N amoniacal (mg \%) & 0,82 & 1,96 & 0,69 & 1,45 & 0,4784 \\
Escore & 2,00 & 2,43 & 2,04 & 2,10 & 0,0229 \\
CV $(\%)$ & & & & & 96,00 \\
\hline
\end{tabular}

*Teste de Kruskal-Wallis- significância p< 0,05.

A concentração de nitrogênio amoniacal nas fezes dos gatos foi semelhante independentemente dos tratamentos $(p>0,05)$. É importante considerar que a alta variabilidade do resultado de mensuração dessa característica pode ter influenciado na ausência de diferenças estatísticas, já que a concentração numérica no tratamento de $0,4 \%$ foi menos da metade da maior concentração observada no tratamento de $0,2 \%$. Essa característica corrobora os resultados de mensuração dessas substâncias relatadas por SWANSON et al. (2002) que creditaram esse acontecimento à baixa concentração desses metabólitos nas fezes. Assim, em futuros experimentos um número maior de animais pode ser necessário para avaliar com maior acurácia o teor fecal de nitrogênio amoniacal. 
Ressalta-se que os resultados encontrados estão de acordo com os verificados por SWANSON et al. (2002), ao utilizarem $0,3 \%$ de mananoligossacarídeo em dietas para cães. Dietas para gatos possuem naturalmente altos níveis de proteína (no presente estudo, $34 \%$ da matéria seca da dieta) que, associada à particularidade dos felinos quanto ao metabolismo proteico, poderiam ter contribuído para que diferenças maiores sobre a concentração de nitrogênio amoniacal não fossem observadas. HESTA et al. (2003), estudando frutoligossacarídeos, também observaram o mesmo efeito inibidor de níveis elevados de proteína na dieta sobre a redução de amônia nas fezes de cães.

Para o escore de redução de odor, observouse um ligeiro efeito positivo da inclusão de $0,2 \%$ de EPL na dieta. Os voluntários atribuíram uma média de escore de 2,40 para as fezes provenientes de animais do tratamento 2 , o que a colocaria entre as classificações de igual ao padrão e ligeiramente melhor que o padrão. Os tratamentos com 0,4 e $0,6 \%$ de EPL também apresentaram escores ligeiramente superiores que as fezes dos animais controle $(2,04 \mathrm{e}$ 2,10, respectivamente), no entanto, sem efeito estatístico significativo ( $>>0,05)$. De forma inesperada, os voluntários classificaram a amostra que apresenta numericamente o maior teor de nitrogênio amoniacal como a que demonstrou o melhor potencial para a redução de odores.

O modelo sensorial desenvolvido por MAIA et al. (2010) foi adaptado da análise sensorial de alimentos descritas por MORALES (1994) e utilizado para mensurar os efeitos da Yucca schidigera sobre a redução do odor de fezes de cães da raça Beagle. Esses testes atribuem valores às amostras que são comparadas em relação ao padrão (correspondente às fezes provenientes do tratamento controle). A escala varia de 0 a 10 em que os números de 0 a 4 indicam amostras extremamente piores, muito piores, regularmente piores ou ligeiramente piores que o padrão, 5 indica amostras iguais ao padrão e de 6 a 10 amostras ligeiramente melhores, regularmente melhores, muito melhores ou extremamente melhores, respectivamente. Por esse motivo, pode haver subjetividade relacionada à percepção sensorial e aos fatores ambientais, como presença de animais em casa, inerentes a cada um dos avaliadores participantes da pesquisa. Apesar disso, auxilia na avaliação da percepção do proprietário quanto à redução de odor e pode ser aliado a métodos químicos (como a determinação de aminas biogênicas e demais compostos) para um quadro mais completo dos efeitos de substâncias com potencial de redução de odor. Trabalho semelhante ao de MAIA et al. (2010) foi realizado em gatos por ROQUE et al. (2011). Nessa metodologia procurou-se diminuir a escala de valores (de 0 a 4), facilitando dessa forma a classificação das amostras pelos avaliadores. Essa foi a metodologia seguida neste trabalho.

Excluindo-se a subjetividade do teste sensorial, sugere-se que o resultado encontrado pode ser atribuído a uma combinação de diversas substâncias que, além dos compostos oriundos do metabolismo proteico (como amônia, aminas biogênicas, indóis e outros), também incluem os ácidos graxos, sendo que a junção de todos esses elementos é mais importante do que a presença ou ausência de um componente isolado (LOWE et al., 1997)

No presente experimento, a concentração total de ácidos graxos de cadeia curta, inclusive o acético, foi menor no tratamento de $0,2 \%$, o que pode ter contribuído para uma resposta positiva por parte dos examinadores. Embora o limiar para a percepção de ácidos graxos $(6,9 \mathrm{mg} / \mathrm{L}$ para o acético) seja bem maior que para a amônia $(1 \mu \mathrm{g} / \mathrm{L})(\mathrm{LOWE}$ et al., 1997), a dieta comercial seca com inclusão de $0,2 \%$ EPL pode ter interferido positivamente sobre a combinação das substâncias componentes do mau odor.

As concentrações totais médias de AGCC encontram-se dentro dos padrões estabelecidos para felinos alimentados com dietas comerciais que são normalmente inferiores a $600 \mathrm{mmol}$ (BROSEY et al., 2000). A proporção molar média foi de $65,23 \%$ para o acético; $23,94 \%$ para o propiônico e $10,82 \%$ para o butírico, que são valores semelhantes aos descritos por SWANSON et al. (2002) para cães. Nenhum efeito da inclusão de EPL na dieta foi encontrado sobre as concentrações de AGCC, mas a proporção de ácido propiônico foi significativamente alterada pela dieta. No entanto, o $\mathrm{R}^{2}$ foi baixo e não permitiu o ajuste de equações de regressão. Esses resultados são contrastantes com os observados em outras espécies. Em perus, por exemplo, a concentração de ácidos graxos totais foi significativamente menor em animais alimentados com EPL por uma diminuição na concentração de ácido propiônico (ZDUNCZYK et al., 2005).

Os resultados para a concentração de ácidos graxos de cadeia curta (acético, propiônico e butírico) estão demonstrados na Tabela 3 .

Os ácidos graxos de cadeia curta são provenientes da fermentação bacteriana no cólon especialmente de carboidratos e aminoácidos (COMMANE et al., 2005) e o ácido lático é um dos principais produtos desse processo. A manutenção da população de bactérias láticas bem como a não interferência sobre o número de $E$. coli pode ter contribuído para a obtenção de resultados similares nas concentrações totais. A alteração na proporção 
molar de ácido propiônico poderia ter sido decorrente da ação do mananoligossacarídeo da EPL sobre espécies bacterianas propiônicas; no entanto, é importante considerar que o coeficiente de determinação da equação foi baixo. Em humanos e cães, uma das principais bactérias com essa característica são as bifidobactérias; entretanto, em felinos, o seu isolamento é mais difícil e suas concentrações menores (RASTALL et al., 2004). Um fator que poderia explicar esse resultado seria uma melhor eficiência na conversão do ácido lático a AGCC nos tratamentos de 0,2 e $0,4 \%$ de EPL já que embora diferenças significativas não tenham sido encontradas, o ácido butírico seguiu o mesmo padrão do propiônico. Assim, estudos sobre a microbiota intestinal de felinos domésticos e o seu comportamento na produção de ácidos graxos de cadeia curta são necessários e poderão esclarecer esses pontos no futuro.

Tabela 3: Concentração (mmol/g MS) de ácidos graxos de cadeia curta em função dos níveis de inclusão de extrato de parede de levedura (EPL) adicionados à dieta empregada no estudo

\begin{tabular}{lcccccccc}
\hline & \multicolumn{4}{c}{ Tratamentos (\% EPL) } \\
Variável & 0 & 0,2 & 0,4 & 0,6 & $\mathrm{CV}$ & $\mathrm{L}$ & $\mathrm{Q}$ & $\mathrm{D}$ \\
\hline Total & 441,19 & 313,60 & 420,56 & 381,72 & 6,90 & 0,9100 & 0,4635 & 0,5003 \\
Acético & 285,38 & 210,45 & 275,00 & 243,35 & 6,18 & 0,1828 & 0,0650 & 0,7268 \\
Propiônico & 120,16 & 58,92 & 93,31 & 105,23 & 11,72 & 0,8578 & 0,0667 & 0,2941 \\
Butírico & 35,65 & 44,22 & 52,24 & 33,14 & 22,57 & 0,5751 & 0,3590 & 0,9225 \\
\% Acético & 64,27 & 67,26 & 65,87 & 64,08 & 5,59 & 0,7946 & 0,1684 & 0,5982 \\
\% Propiônico & 27,99 & 19,22 & 22,17 & 26,49 & 28,01 & 0,9034 & $0,0313^{1}$ & 0,4158 \\
\% Butírico & 7,75 & 13,53 & 11,95 & 9,43 & 60,11 & 0,7943 & 0,1740 & 0,6305 \\
\hline
\end{tabular}

p*: significância p< 0,05; CV: coeficiente de variação; L:efeito linear; Q: efeito quadrático; D: efeito desvio. ${ }^{1}{ }^{2}=0,2819$

\section{CONCLUSÃO}

O uso de extrato de parede de levedura até o nível de $0,6 \%$ não altera a microbiota fecal, concentração de ácidos graxos de cadeia curta e nitrogênio amoniacal. No entanto, ressalta-se que o acréscimo de EPL em até $0,6 \%$ em dieta seca promove redução do odor das fezes. Outros estudos são necessários para avaliar os mecanismos de ação e as doses adequadas desse aditivo para gatos adultos.

\section{REFERÊNCIAS}

ASSOCIATION OF OFFICIAL ANALYTICAL CHEMISTS, I. Official Methods of Analysis. Arlington, VA. 16 ed, 1995

BASSAN, J.D.L.; FLÔRES, M.L.; ANTONIAZZI, T.; BIANCHI, E.; KUTTEL, J.; TRINDADE, M.M. Controle da infecção por Salmonella Enteritidis em frangos de corte com ácidos orgânicos e mananoligossacarídeo. Ciência Rural, v.38, 1961-1965, 2008.

BRASIL. Portaria ANVISA n ${ }^{\circ}$ 518, de 25 março de 2004, Estabelece os procedimentos e responsabilidades relativas ao controle e vigilância da qualidade da água para o consumo humano e seu padrão de potabilidade e dá outras providências. Portaria $n^{\circ}$ 518. Diário Oficial da República Federativa do Brasil. Brasília, DF, 26 março,
2004.

BROSEY, P.B; HILL, R.C; SCOTT, K.C. Gastrointestinal volatile fatty acid concentrations and $\mathrm{pH}$ in cats. American Journal of Veterinary Research, v. 61, p. 359-361, 2000.

COMMANE, D; HUGHES , R; SHORTT, C; ROWLAND, I. The potential mechanisms involved in the anti-carcinogenic action of probiotics. Mutation Research, v. 591, p. 276-289, 2005.

ERWIN, E. S., MARCO, G. J; EMERY, E. M. Volatile fatty acid analyses of blood and rumen fluid by gas chromatography. Journal of Dairy Science, v. 44, p. 1768-1771, 1961

FINUCANE, M; SPRING, P; NEWMAN, K. Incidence of mannose-sensitive adhesins in enteric bacteria. Poultry Science. v. 78, p. 139 (Abst), 1999.

GIBSON， G.R; PROBERT, H.M; VAN LOO， J; RASTALL, R.A; ROBERFROID M.B. Dietary modulation of the human colonic microbiota: updating the concept of prebiotics. Nutrition Research Reviews. v. 17, p. $259-275,2004$.

HESTA, M; ROOSEN, W; JANSSENS, G.P.J; MILLET, S; WILDE, R. Prebiotics affect nutrient digestibility but not faecal ammonia in dogs fed increased dietary protein levels. British Journal of Nutrition, v. 90, p. 1007-1014, 2003.

HOLT, J.G et al. Bergey's manual of determinative 
bacteriology. Baltimore: Willians Wilkins, 9 $9^{\text {a }}$ ed,1994. $787 \mathrm{p}$.

LAFLAMME D. "Development and validation of a body condition score system for cats: A clinical tool. Feline Practice; v.25, p.13-18, 1997

LEE, K; LIM, C.Y; TENG, W. L; OUWEHAND, A.C; TUOMOLA, E. M; SALMINEN, S. Quantitative approach in the study of adhesion of lactic acid bacteria to intestinal cells and their competition with enterobacteria. Applied and Environmental Microbiology, v. 66, p. 3692-3697, 2000.

LOWE, J.A; KERSHAW, S.J. The ameliorating effect of Yucca schidigera extract on canine and feline faecal aroma. Research in Veterinary Science, v. 63, p. 61-66, 1997.

MAIA, G.V.C; SAAD, F. M. O. B.; ROQUE, N. C.; FRANÇA, J; LIMA, L.M.S; AQUINO, A. A. Zeólitas e Yucca schidigera em rações para cães: palatabilidade, digestibilidade e redução de odores fecais. Revista Brasileira de Zootecnia, v.39, p.2442 - 2444, 2010.

MIDDELBOS, I.S; GODOY, M.R; FASTINGER, N.D; FAHEY, G.C.Jr. A dose-response evaluation of spraydried yeast cell wall supplementation of diets fed to adult dogs: Effects on nutrient digestibility, immune indices, and fecal microbial populations. Journal of Animal Science, v. 85, p. 3022-3032, 2007.

NATIONAL RESEARCH COUNCIL. Nutrient requirements of dogs and cats. Washington, D.C: National Academy of Science, National Academy Press, 2006. 398 p.

RASTALL, R.A. Bacteria in the gut: friends and foes and how to altere the balance. Journal of Nutrition, $v$. 134, p. 2022S-2026S, 2004.
ROQUE, N.C; SAAD, F.M.O.B; SANTOS, J.P.F; EBINA, F.S; CHIZZOTTI, A.F; SILVA, R.C; AQUINO, A.A; MAIA, G.V.C. Increasing levels of zeolite and Yucca schidigera in diets for adult cats. Revista Brasileira de Zootecnia, v.40, p.2471-2475, 2011.

SAS Institute Inc. SAS User's guide: statistics. Ver. 9.1.1, SAS Inst., Cary, NC, 2004.

SILVA, N; JUNQUEIRA, V.C.A; SILVEIRA, N.F.A. Manual de métodos de análises microbiológicas de alimentos. $2^{\mathrm{a}}$ ed. São Paulo: Varela, 2001. 295p.

SWANSON,K.S;GRIESHOP,C.M; FLICKINGER, E.A; BAUER, L.L; HEALY, H.P; DAWSON, K.A; MERCHEN, N.R; FAHEY, G.C. Jr. Supplemental frutooligossacharides and mannanoligossaccharides influence immune function, ileal and total tract nutrients digestibilities, microbial populations and concentrations of protein catabolites in the large bowel of dogs. Journal of Nutrition. v. 132, p. 980-989, 2002.

TELLEZ, G; HIGGINS, S.E; DONOGHUE, A.M; HARGIS, B.M. Digestive physiology and the role of microorganisms. The Journal of Applied Poultry Research, v.15, p. 136-144, 2006.

TORTORA, G.J; FUNKE, B.R; CASE, C.L. Microbiologia. $6^{\mathrm{a}}$ ed. Porto Alegre: Artmed, 2002. 827 p.

WALKER, W.A; DUFFY, L.C. Diet and bacterial colonization: Role of probiotics and prebiotics. The Journal of Nutrional Biochemistry, v. 9. p.668-675, 1998.

ZDUNCZYK，Z; JUSKIEWICZ，J; JANKOWSKI，J; BIEDRZYCKA, E; KONCICKI, A. Metabolic response of the gastrointestinal tract of turkeys to diets with different levels of mannan-oligosaccharide. Poultry Science, v. 84, p. 903-909, 2005. 